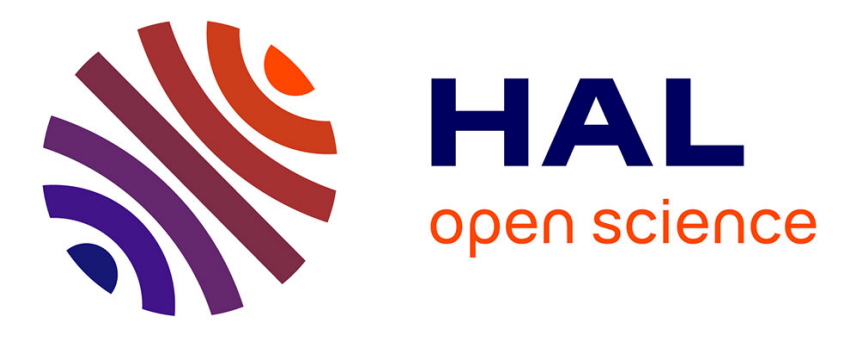

\title{
trans to cis photo-isomerization in merocyanine dysprosium and yttrium complexes
}

\author{
Pramila Selvanathan, Vincent Dorcet, Thierry Roisnel, Kevin Bernot, Gang
} Huang, Boris Le Guennic, Lucie Norel, Stéphane Rigaut

\section{- To cite this version:}

Pramila Selvanathan, Vincent Dorcet, Thierry Roisnel, Kevin Bernot, Gang Huang, et al.. trans to cis photo-isomerization in merocyanine dysprosium and yttrium complexes. Dalton Transactions, 2018, 47 (12), pp.4139-4148. 10.1039/c8dt00299a . hal-01744292

HAL Id: hal-01744292

https://hal-univ-rennes1.archives-ouvertes.fr/hal-01744292

Submitted on 29 May 2018

HAL is a multi-disciplinary open access archive for the deposit and dissemination of scientific research documents, whether they are published or not. The documents may come from teaching and research institutions in France or abroad, or from public or private research centers.
L'archive ouverte pluridisciplinaire HAL, est destinée au dépôt et à la diffusion de documents scientifiques de niveau recherche, publiés ou non, émanant des établissements d'enseignement et de recherche français ou étrangers, des laboratoires publics ou privés. 


\title{
Trans to cis photo-isomerization in merocyanine dysprosium and yttrium complexes.
}

\author{
Pramila Selvanathan, ${ }^{[a]}$ Vincent Dorcet, ${ }^{[a]}$ Thierry Roisnel, ${ }^{[a]}$ Kévin Bernot, ${ }^{[a]}{ }^{*}$ Gang Huang, ${ }^{[a]}$ \\ Boris Le Guennic, ${ }^{[a]}$ Lucie Norel ${ }^{[a]}{ }^{*}$ and Stéphane Rigaut ${ }^{[a]^{*}}$
}

[a] Univ Rennes, INSA Rennes, CNRS, ISCR (Institut des Sciences Chimiques de Rennes)UMR 6226, F-35000 Rennes, France

\begin{abstract}
*To whom correspondence should be addressed. E-mail: kevin.bernot@insa-rennes.fr, lucie.norel@univ-rennes1.fr, stephane.rigaut@univ-rennes1.fr.
\end{abstract}

\section{RECEIVED DATE (to be automatically inserted after your manuscript is accepted if required according to the journal that you are submitting your paper to)}

\footnotetext{
Abstract. We report the synthesis of two lanthanide complexes including a chelating merocyanine (MC) ligand and obtained from the reaction of a bis(pyridinemethyl)amine substituted spiropyran with yttrium(III) or dysprosium(III) triflate salts, which structures were confirmed both in solid state and in solution by single crystal X-ray diffraction studies and NMR investigations. The obtained merocyanine metal complexes can reversibly undergo a phototriggered transformation consisting of a partial isomerization of the trans-merocyanine ligand to
} 
its cis isomer (cis-MC) providing complexes in which the metal-phenolate bond is retained. SQUID magnetometry experiments in combination with ab initio calculations were used to evidence and rationalize single molecule magnet behavior of the dysprosium complex and to probe the changes in the dysprosium ion local environment upon photo-isomerization.

\section{SYNOPSIS TOC}
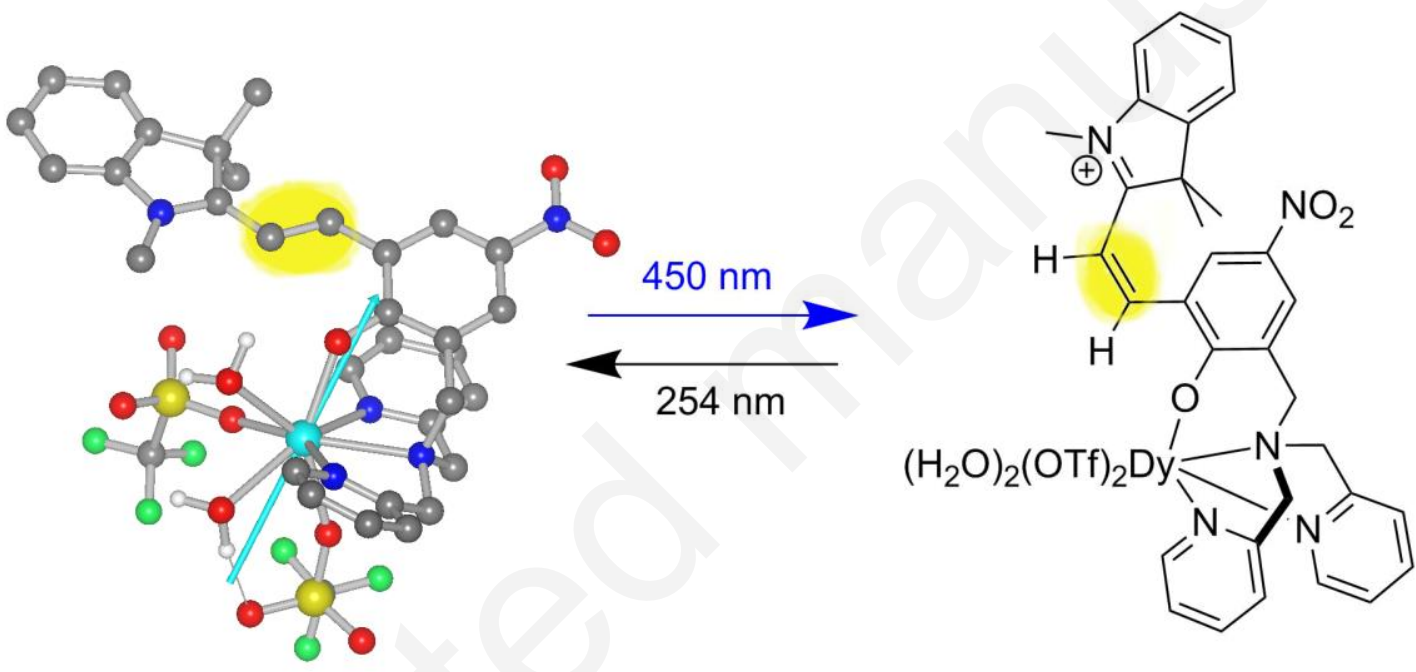

Keywords: photochromism, spiropyran, mercocyanine, lanthanide, single molecule magnet, ab initio calculations.

\section{Introduction}

Spiropyran (SP) is one of the most popular classes of photochromic molecules. ${ }^{[1]}$ Because of the important changes in both structure and electronic properties upon light induced isomerization to their merocyanine (MC) forms, ${ }^{[2]}$ they have been widely used for a diversity of applications including sunlight adaptive lenses ${ }^{[1 \mathrm{a}]}$, bio-imaging, ${ }^{[3]}$ and for the development of smart materials. ${ }^{[4]}$ The MC form is suitable to generate metal complexes with both $d$ and $f$ metal 
ions $^{[1 \mathrm{dd}, 1 \mathrm{f}, 5]}$ but spectroscopic and crystallographic evidences of the detailed molecular structure of these complexes are scarce, with the notable exception of a recent study on divalent $3 d$ metal ions. ${ }^{[6]}$ Such light responsive metal complexes have a great potential as switchable contrast agents ${ }^{[7]}$ and for sensing applications. ${ }^{[1 d]}$

Meanwhile, Single Molecule Magnets (SMM), which behave at low temperature as tiny magnets at the molecular scale, have raised enormous interest in recent years. ${ }^{[8]}$ Their memory effect, due to slow magnetic relaxation, is directly linked to the magnetic anisotropy of the molecule. Actually, based on a single anisotropic lanthanide ion, highly anisotropic complexes with SMM behavior can be created. ${ }^{[9]}$ In these complexes, the barrier to slow magnetic relaxation originates from magnetic ground state splitting caused by the crystal field so that the improvement of SMM behavior relies on the design of adequate coordination environment. ${ }^{[10]}$ This strong environment dependence can provide a handle for the external control of lanthanide complexes' magnetic characteristics with light, through the photo-induced modification of the metal coordination (crystal field), an idea which is raising more and more attention but that has not reached satisfying criteria so far. ${ }^{[11]}$ In our current efforts towards such switchable magnetic materials, we have been interested in lanthanide-based complexes bearing a SP/MC switchable ligand. We have recently reported that a $\mathrm{MC}$ isomer, with additional chelating group, can provide strong binding to a dysprosium(III) ion to generate a very large magnetic anisotropy, and in fine a remarkable single molecule magnet behavior. ${ }^{[12]}$ However, due to the irreversible release of the metal ion under visible irradiation, the SP form of the complex could not be generated and no further photomagnetic commutation was realized. Therefore, in order to design more efficient and reversible photoswitchable systems able to retain metal coordination, deeper studies and understanding of the interplay between metal binding and photo-isomerization are highly desirable. In purely organic systems, photochemical isomerization processes of SP/MC systems 
are well documented. ${ }^{[13]}$ In particular, the ring opening/closing reactions are known to proceed through a cis-MC intermediate (scheme 1$),{ }^{[5 a, 14]}$ which can be trapped in a hindered environment provided by polymers, ${ }^{[15]}$ or macrocyclic hosts. ${ }^{[16]}$ In the latter case, the $c i s-\mathrm{MC}$ to SP conversion is prevented by a cavity effect favouring the unreactive protonated $c i s$-merocyanine $c i s-\mathrm{MCH}^{+}$. In contrast, in the case of polydentate MC metal complexes implying a phenolate-metal coordination bond, little is known about the isomerization event and particularly about the features that allow to selectively break up this metal-oxygen bond to allow isomerization towards the SP form of the complex, or on the contrary, that prevent or limit isomerization because of a too strong metal binding. ${ }^{[5]}$

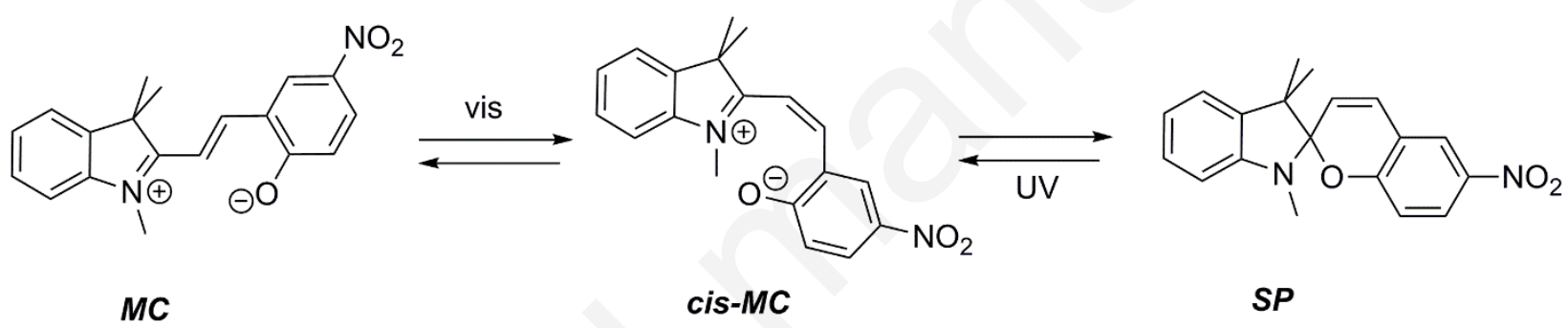

Scheme 1 general pathway for photo-isomerization in organic MC/SP.

Herein, in the course of improving the stability upon photoisomerization of our previously described lanthanide complexes bearing a chelating MC ligand and hfac ligands (scheme 2), we explore a modified complex obtained from the reaction of the bis(pyridinemethyl)amine substituted spiropyran with yttrium(III) or dysprosium(III) triflate (OTf-) salts. We show that the obtained MC metal complexes can now undergo a reversible phototriggered transformation in which the metal-phenolate bond is maintained that unexpectedly consists of a limited isomerization of the trans-MC ligand to the cis-MC complex, without reaching the SP complex. In particular, we use SQUID magnetometry experiments in combination with ab initio calculations i) to evaluate the ability of the dysprosium complex to behave as a single molecule 
magnet, and ii) to probe the changes in the dysprosium ion local environment upon photoisomerization.

\section{Results and Discussion}

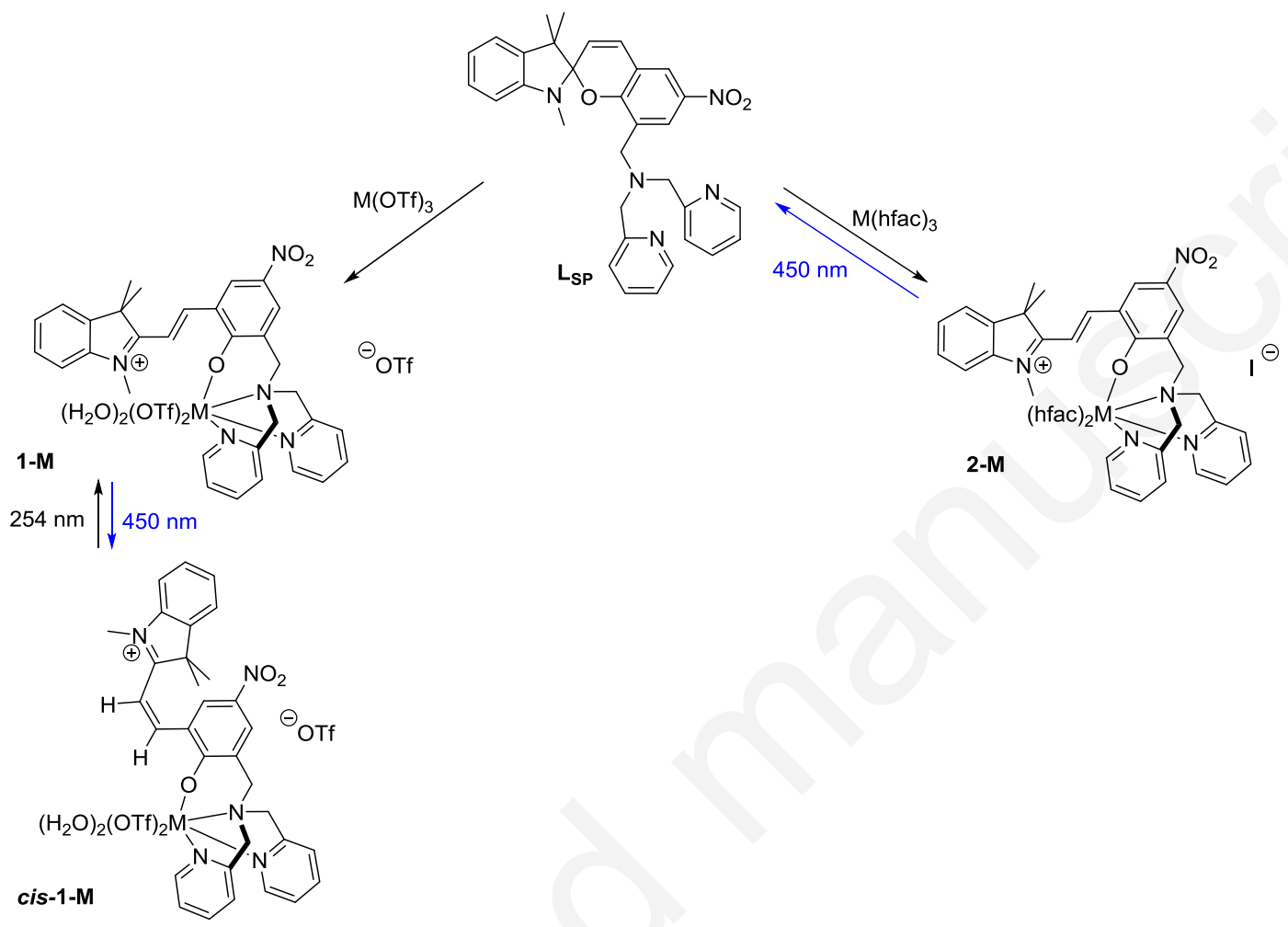

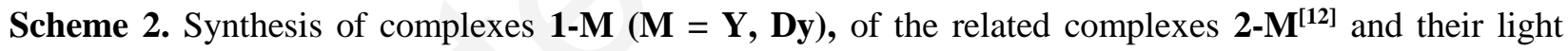
induced behavior.

Synthesis and characterization. The synthesis of the new complexes $1-\mathbf{M}(\mathbf{M}=\mathbf{D y}, \mathbf{Y})$ were performed in dichloromethane from reaction of $\left[\mathrm{M}(\mathrm{OTf})_{3}\right]$ precursors with ligand $\mathbf{L} \mathbf{s P}$ in equimolar quantities (scheme 2). Single crystals formed at room temperature from the evaporation of the crude dichloromethane solutions (in $30 \%$ yield for 1-Dy and $42 \%$ for 1-Y). These new compounds were fully characterized with the help of ${ }^{1} \mathrm{H}$ NMR $(\mathrm{M}=\mathrm{Y}$, see next section), IR spectroscopies, elemental analysis, HR-MS and XRD studies. As previously observed in the case of coordination of $\left[\mathrm{M}(\mathrm{hfac})_{3}\right]$ precursors, ion-induced ring-opening to the 
merocyanine form of the ligand $\mathbf{L}_{\mathbf{M C}}$ occurs (scheme 2) leading to 1-M complexes with the general formula $\left[\mathrm{M}\left(\mathbf{L M C}_{\mathbf{M C}}\right)(\mathrm{OTf})_{2}\left(\mathrm{H}_{2} \mathrm{O}\right)_{2}\right] \mathrm{OTf}$. Therefore, their IR spectra show a broad O-H stretching band at around $3300 \mathrm{~cm}^{-1}$ due to the presence of two water molecules and typical C-F stretching bands for the triflate ions at 1026 and $635 \mathrm{~cm}^{-1}$.

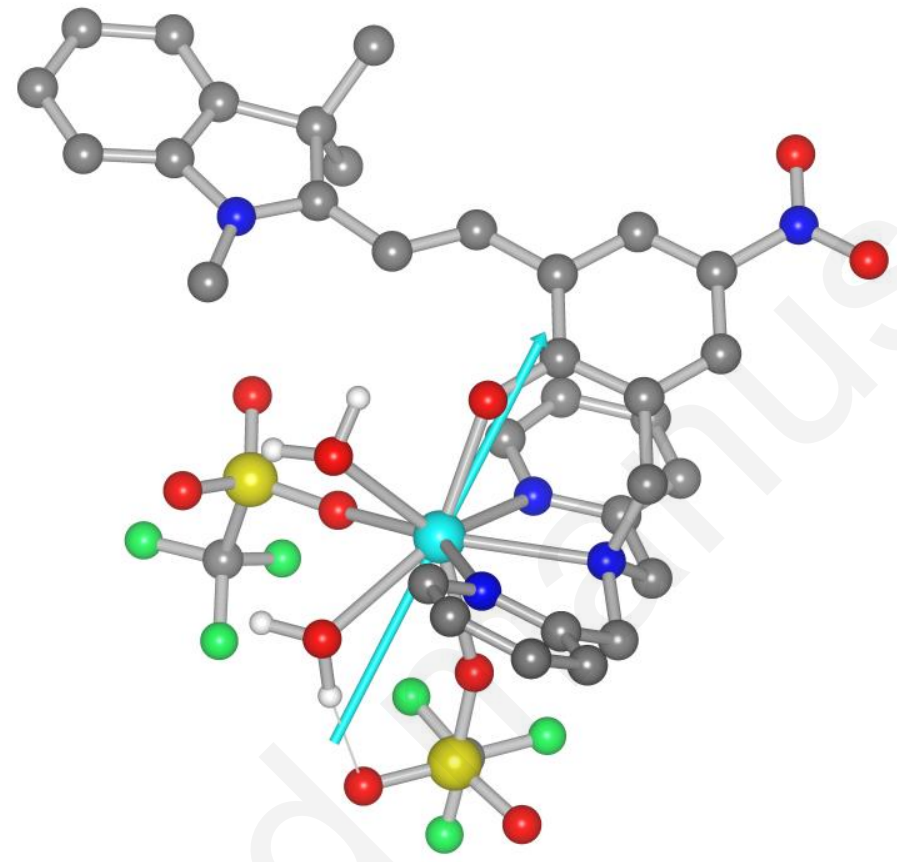

Figure 1. View of the XRD structure of 1-Dy. Grey, blue, red, yellow, green and light blue spheres represent $\mathrm{C}, \mathrm{N}, \mathrm{O}, \mathrm{S}, \mathrm{F}$ and Dy atoms, respectively. Only hydrogen atoms of water molecules are shown (white spheres). The direction of the magnetic anisotropy axis is shown as a light blue arrow.

Both complexes crystallize in the trigonal space group R-3 and are isostructural (Table S1). For concision, only the structure of 1-Dy is described here. Specifically, the merocyanine state of the ligand is clearly evidenced from bond lengths and angles. ${ }^{[12]}$ With three nitrogen atoms of the bis(2-pyridinemethyl)amine moiety and the phenolate oxygen atom involved in coordination bonds, the merocyanine acts as a tetradentate ligand. Two oxygen atoms from the two triflate ligands and from two water molecules complete the coordination sphere of the metal. The Dy-O 
bond length values are between 2.31 and $2.33 \AA$ for the oxygen of the triflate ligands, between 2.39 and $2.41 \AA$ for the two water molecules, whereas Dy-N bonds are longer than $2.52 \AA$. As expected, the phenolate oxygen experiences the shortest bond to the metal center $(2.22 \AA)$ due to its hard Lewis base character. The resulting geometry of the N3O5 coordination sphere is very close to a triangular dodecahedron $\left(\mathrm{D}_{2 \mathrm{~d}}\right)$ as shown by a CSM parameter of $0.845 .{ }^{[17]}$ With two anionic triflate and one neutral MC ligand, the title complexes are cationic and one triflate anion is found as counterion in the solid state. Because of $\mathrm{H}$ bonding between water molecules and triflate ions, the complexes are arranged in hexagonal channels along the $c$ axis in which free triflate ions lie, together with disordered solvent molecules (Figure S1).

\section{UV-vis and NMR spectroscopic characterizations and photo-isomerization studies of 1-M} $(\mathbf{M}=\mathbf{D y}, \mathbf{Y})$. The absorption spectra of $\mathbf{1 - M}$ complexes were measured in acetonitrile solutions (Figure 2 for 1-Dy). These two complexes show identical spectra with two strong absorption bands at $\lambda_{\max }=354 \mathrm{~nm}\left(\varepsilon=16670 \mathrm{~mol}^{-1} \cdot \mathrm{L} \cdot \mathrm{cm}^{-1}\right)$ and $\lambda_{\max }=462 \mathrm{~nm}\left(\varepsilon=18260 \mathrm{~mol}^{-1} \cdot \mathrm{L} \cdot \mathrm{cm}^{-1}\right)$. The second transition, characteristic of a coordinated merocyanine isomer is blue shifted as compared with the one observed for the free merocyanine ligand $\mathbf{L}_{\mathbf{M C}}\left(\lambda_{\max }=554 \mathrm{~nm}\right)$. The position of this band is usually dependent on the relative contribution of the neutral quinoidal and polar zwitterionic resonance structures of the MC structure and is strongly solvatochromic. The quinoidal form is preferentially stabilized in non-polar media, and the subsequent decrease of the energy gap between the ground and excited states of MC results in a red shift. ${ }^{[4 \mathrm{a}]}$ On the contrary, protonation or metal coordination induces a hypsochromic shift as observed here. 


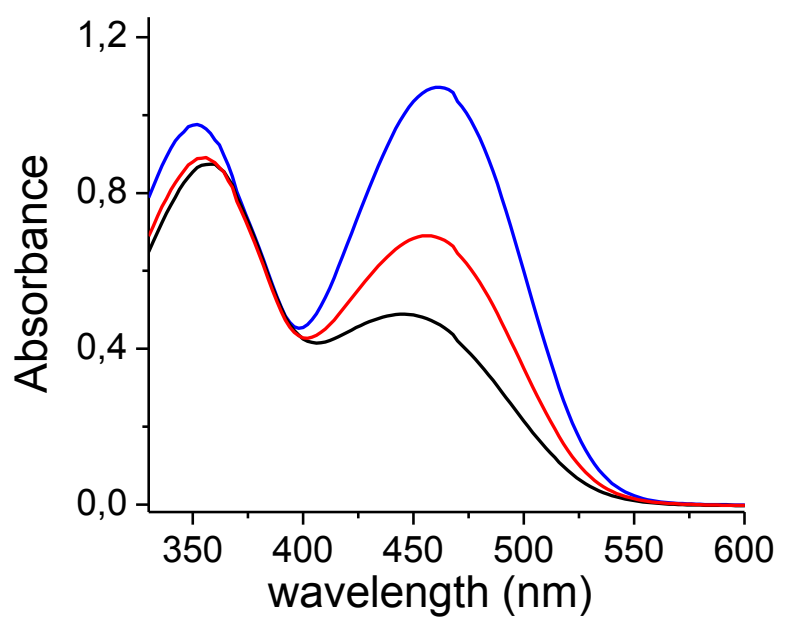

Figure 2: Electronic absorption spectra of 1-Dy in acetonitrile solution (blue curve), after $450 \mathrm{~nm}$ irradiation (black curve), and further $254 \mathrm{~nm}$ irradiation (red curve).

In acetonitrile, upon irradiation at $\lambda=450 \mathrm{~nm}$ for 2 minutes, the band at $\lambda_{\max }=462 \mathrm{~nm}$ decreases to $42 \%$ of its initial absorbance value with a slight blue shift $\left(\lambda_{\max }=448 \mathrm{~nm}\right)$. This process is partially reversible with further irradiation at $\lambda=254 \mathrm{~nm}$ for 3 minutes leading to a recovery of $64 \%$ of the initial absorbance with $\lambda_{\max }=457 \mathrm{~nm}$ (Figure 2). Therefore, these results suggest that 1-M complexes can undergo photoisomerization to a compound with a different optical response (lower absorbance, lower $\lambda_{\max }$ ) that is partially converted back to the initial state after UV irradiation. The isomerization process was then followed by NMR in order to identify the nature of the photogenerated species.

First, in the case of 1-Y, ${ }^{1} \mathrm{H}$ NMR spectra recorded in $d^{6}$-acetone or $d^{3}$-acetonitrile show very similar features and confirm the proposed structure for 1-M. The main features in the case of $d^{3}$ acetonitrile are shown in Figure 3. First, the merocyanine isomer is clearly evidenced with the vinyl proton $\left(\mathrm{H}_{\mathrm{a}}\right.$ and $\left.\mathrm{H}_{\mathrm{b}}\right)$ signals at 8.14 and $7.77 \mathrm{ppm}$ with $\mathrm{J}=16.0 \mathrm{~Hz}$, typical of trans coupling. ${ }^{[5 b]}$ Second, the pyridine protons appear as broad signals at $8.9,7.8$ and 7.4 ppm and 
pyridyl- $\mathrm{CH}_{2}-\mathrm{N}$ protons $\left(\mathrm{H}_{\mathrm{e}}\right.$ and $\mathrm{H}_{\mathrm{e}}$ ) appear as a set of strongly coupled doublets at 4.66 and 4.14 ppm (AB system) instead of a singlet in the free ligand LsP. This results from the metal coordination freezing the rotation of the pyridyl unit in a geometry in which the two picolyl arms are equivalent. Similarly, owing to the loss of chirality due to the spiro carbon atom in LsP, the phenyl- $\mathrm{CH}_{2}-\mathrm{N}$ protons $\left(\mathrm{H}_{\mathrm{d}}\right)$ appear as a broad singlet (at $3.73 \mathrm{ppm}$ ) in the spectrum of 1-Y instead of a strongly coupled AB system in the free ligand LsP. Finally, the ${ }^{19} \mathrm{~F}$ NMR spectrum showed a sharp peak at $-79.2 \mathrm{ppm}$ for the triflate anions, which probably results from fast exchange between coordinated and free triflate ions in solution at room temperature. The ${ }^{1} \mathrm{H}$ data obtained after irradiation at $450 \mathrm{~nm}$ show the partial conversion of $\mathbf{1 - Y}$ to a single species that we ultimately determined to be the cis isomer of the complex, cis-1-Y (Figure 3). Indeed, the isomerization of $\mathbf{1 - Y}$ to a complex bearing the photochromic ligand in its spiropyran form or a decoordination to the free ligand LsP could be ruled out on the basis of the following observations. First, a coupling constant of $12.4 \mathrm{~Hz}$ was observed for the doublet at $6.55 \mathrm{pm}$ assigned to $\mathrm{H}_{\mathrm{a}}$ or $\mathrm{H}_{\mathrm{b}}$ while $\mathbf{L}$ SP shows a coupling constant of $10.3 \mathrm{~Hz}$ (doublet at 6.92 and 5.87 ppm). Next, only one signal with the correct integration ratio could be assigned to the $\mathrm{H}_{\mathrm{c}}$ methyl protons at a chemical shift compatible with the merocyanine isomer (1.70 ppm). Indeed, in spiropyran isomers, the two methyl groups are diastereotopic due to the asymmetric spiro-carbon and they are typically observed as two singlets at lower chemical shifts $(1.27$ and $1.21 \mathrm{ppm}$ for LsP). Lastly, the multiplicity of $\mathrm{H}_{\mathrm{d}}$ and $\mathrm{H}_{\mathrm{e} / \mathrm{e}}$, signals was maintained in the photo-induced species as compared with 1-Y. Proton $\mathrm{H}_{\mathrm{e}}$ and $\mathrm{H}_{\mathrm{e}}$, display two doublets $(\mathrm{J} \approx 15 \mathrm{~Hz})$, each integrating for $2 \mathrm{H}$, respectively shifted by -0.13 and +0.05 ppm upon $450 \mathrm{~nm}$ irradiation, and $\mathrm{H}_{\mathrm{d}}$ shows as a broad singlet shifted by $0.04 \mathrm{ppm}$. Therefore, these latter minor chemical shifts changes strongly support the fact that the nature of the coordination sphere is maintained: because the photoisomerization to cis-1-Y event occurs at the periphery of the coordination sphere, it does not 
impacts significantly $\mathrm{H}_{d}$ and $\mathrm{H}_{\mathrm{e} / \mathrm{e}}$. Only the double bond proton $\left(\mathrm{H}_{\mathrm{a}} / \mathrm{H}_{\mathrm{b}}\right)$ experience a large change in its chemical shift after $450 \mathrm{~nm}$ irradiation and shows a coupling constant of $12.4 \mathrm{~Hz}$ as expected for a cis $\mathrm{MC}$ isomer. Based on the integration ratio of the $\mathrm{H}_{\mathrm{c}}$ protons in the two isomers, the content of the photo-generated state was calculated to be $22: 78$ 1-Y/cis-1-Y. Finally, the back isomerization process could be obtained either thermally to reach a 81:19 ratio 1-Y/cis-1-Y mixture or by UV irradiation at $254 \mathrm{~nm}$ to reach a 71:29 ratio 1-Y/cis-1-Y mixture (see experimental section for details). The dysprosium complex could not be investigated by NMR spectroscopy, but as the absorption spectrum of 1-Dy shows the same behavior as 1-Y upon 450 nm and UV irradiations, we assume that the same transformation to cis-1-Dy occurs as further confirmed by the magnetometry analysis (vide infra). 

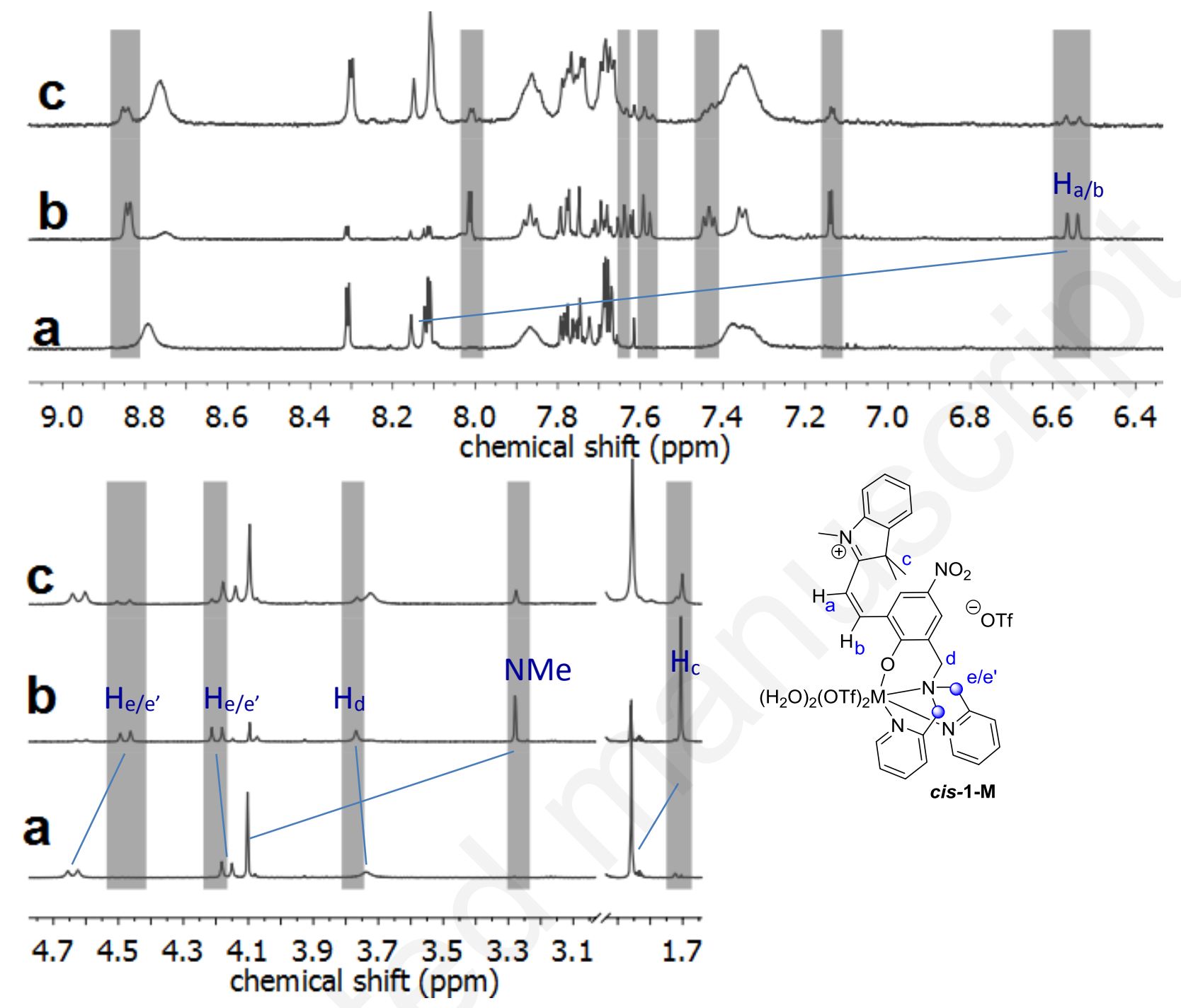

Figure 3: ${ }^{1} \mathrm{H}$ NMR spectra of 1-Y in $d^{3}$-acetonitrile solution $\left(\mathrm{c}=4.710^{-3} \mathrm{~mol} . \mathrm{L}^{-1}\right)$ a) before irradiation, b) after $450 \mathrm{~nm}$ irradiation for 17 hours, c) after subsequently resting in the dark for 14 days. The grey regions of the spectra correspond to the photo-induced species cis-1-Y.

Therefore, in sharp contrast with our previously published lanthanide merocyanine complexes 2$\mathbf{M}$ with hfac ancilary ligands, ${ }^{[12]}$ complexes 1-M can undergo partial isomerization of the MC ligand without noticeable decoordination of the metal center. However, the full transformation from the MC to the SP isomer cannot be reached, probably because of the strong affinity of the lanthanide cation for the phenolate oxygen. To the best of our knowledge, this type of trans to cis 
photo-isomerization has previously been reported only for protonated merocyanine included in cavitands in which the initially formed protonated $c i s-\mathrm{MCH}^{+}$isomer cannot react further in a ring closure process within the host because deprotonation is blocked. ${ }^{[16 \mathrm{~b}, 18]} \mathrm{We}$ are convinced that such a partial transformation in which the spiropyran isomer is not produced could be generalized in the future to other photochromic lanthanide-spiropyran based assemblies and should be kept in mind when re-examining previously published systems for which limited structural or spectroscopic data are available to support the SP <-> MC isomerization processes. ${ }^{[7 b, 19]}$

Magnetic investigation of 1-Dy. In our previous study, complex 2-Dy displayed highly axial magnetic anisotropy and slow relaxation of magnetization. ${ }^{[12]}$ Moreover, the anisotropy axis of this complex, which defines the direction of magnetization preferred orientation, is almost aligned with the dysprosium-phenolate coordination bond. This short bond, also present in 1-Dy, is a key feature to understand the splitting of the magnetic ground state and the resulting energy barrier to slow relaxation of magnetization in 2-Dy. We therefore performed a similar magnetic investigation on 1-Dy by using static (dc) and dynamic (ac) magnetic susceptibility measurements either on solid (1-Dysolid), frozen solution (1-Dysolution) and photo-converted frozen solution (1-Dyphoto). First, investigation on 1-Dysolid by dc magnetic measurements confirms its monometallic character. The room-temperature value of the temperature-molar magnetic susceptibility product, $\chi_{\mathrm{M}} \mathrm{T}_{300 \mathrm{~K}}$, (Figure $\mathrm{S} 2$ ) is $14.23 \mathrm{emu} . \mathrm{K} \mathrm{mol}^{-1}$, in agreement with the expected value (14.17 emu.K.mol $\left.{ }^{-1}\right)$ for one isolated Dy ${ }^{\mathrm{III}}$ ion $\left({ }^{6} \mathrm{H}_{15 / 2}, \mathrm{~S}=5 / 2, \mathrm{~L}=5\right.$, and $\left.\mathrm{g}=4 / 3\right)$. Abinitio investigation (see computational details) confirms these findings with a calculated value of $\chi_{M} \mathrm{~T}_{300 \mathrm{~K}}=13.93 \mathrm{emu} \cdot \mathrm{K} \cdot \mathrm{mol}^{-1}$ (Figure S2). The observed decrease of $\chi_{\mathrm{M}} \mathrm{T}$ when lowering the temperature is assigned to the depopulation of $m_{J}$ sublevels as commonly observed in Dy ${ }^{\text {III }}$ coordination complexes. ${ }^{[10 b, 20]}$ Field dependence of the magnetization (Figure S2) leads to a 
butterfly-like hysteresis loop at $0.47 \mathrm{~K}$ (Figure S3), significantly narrowed when compared to 2Dy. This suggests that 1-Dysolid has less effective SMM properties than 2-Dy. To shed some light on this feature, dynamic magnetic investigations (ac) have been performed. Zero static field $\left(\mathrm{H}_{\mathrm{dc}}\right.$ $=0$ ) measurements reveal frequency dependence of the out-of-phase susceptibility $\chi_{\mathrm{m}}$ ”. However, $\chi_{M}$ " maxima lie outside our investigable frequency window (Figure S4). As for 2-Dy, the most efficient field to slow down the magnetic relaxation is evidenced to be $H_{d c}=1200$ Oe (Figure S5). Under these conditions, clear temperature-dependent out-of-phase susceptibility peaks are observed in the 1.8-15 K temperature range (Figures 4, S6 and S7). Any attempt to fit $\tau$ over the whole temperature range using combination of direct, Raman and/or Orbach relaxation processes failed to provide reasonable results without over-parametrization. This is why we rather provide estimations of a high temperature $(\mathrm{T}>7 \mathrm{~K})$ thermally-dependent Orbach-like relaxation and of a low temperature thermally-independent quantum-tunneling-like relaxation (Figure 5, Table 1). Indeed, above $7 \mathrm{~K}$, fitting with the equation corresponding to an Orbach-like relaxation process $(\tau$ $=\tau_{0} \exp \left(\Delta / \mathrm{k}_{\mathrm{B}} \mathrm{T}\right)$, with $\tau_{0}$ the characteristic relaxation time, $\mathrm{k}_{\mathrm{B}}$ the Boltzmann constant and $\Delta$ the energy barrier for spin reversal) provides $\tau_{0}=1.2410^{-5} \mathrm{~s}$ and $\Delta=32.9 \mathrm{~K}\left(22.9 \mathrm{~cm}^{-1}\right)$ (Figure 5, Table S2). Below $2 \mathrm{~K}, \tau$ reaches a plateau around $\tau_{\text {tunnel }}=0.1 \mathrm{~s}(1.6 \mathrm{~Hz})$. Overall, $\mathbf{1}-\mathbf{D} \mathbf{y}_{\text {solid }}$ shows magnetic relaxation figures one order of magnitude weaker than 2-Dy, which presented a very high energy barrier $\left(\Delta=216 \mathrm{~K}, 150 \mathrm{~cm}^{-1}\right)$ and fast characteristic relaxation time $\tau_{0}\left(\tau_{0}=4.710^{-9} \mathrm{~s}\right)$ with $\tau$ being temperature-dependent on the whole temperature range, including low temperatures. 


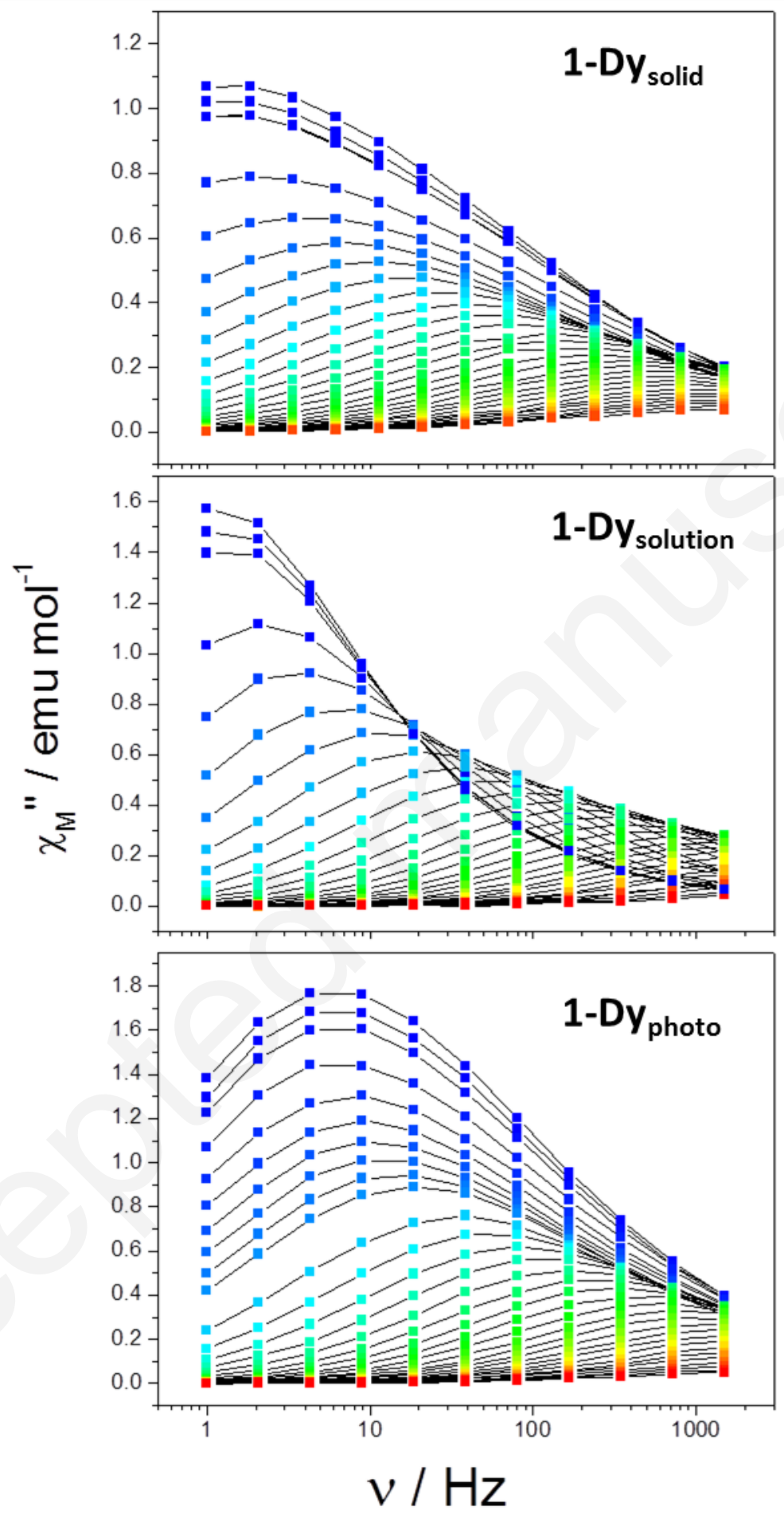

Figure 4: Frequency dependence of the out-of phase magnetic susceptibility ( $\left.\chi_{\mathrm{M}}{ }^{\prime \prime}\right)$ for 1-Dysolid, 1Dysolution, and 1-Dyphoto, measured with $\mathrm{H}_{\mathrm{dc}}=1200$ Oe for temperatures from $1.8 \mathrm{~K}$ (blue) to $15 \mathrm{~K}$ 
(red). Temperature spacing $0.1 \mathrm{~K}(1.8<\mathrm{T}<2 \mathrm{~K})$ and $1 \mathrm{~K}(2<\mathrm{T}<15 \mathrm{~K})$. Lines are guide to the eye.

The analysis of the normalized Cole-Cole plots ( $\chi_{\mathrm{M}}$ ' vs $\chi_{\mathrm{M}}$ " plots) with a Debye model provides the amount of relaxing fraction in the sample $\left(1-\chi_{\mathrm{S}} / \chi_{\mathrm{T}}\right)$, (percentage of the sample that relaxes slowly) and the distribution of relaxation time $\alpha(\alpha=0$ when all molecules relax with the same $\tau$; $\alpha=1$ for a full distribution of $\tau$ ). On 1-Dysolid the percentage of relaxing fraction varies significantly (96\% at $1.8 \mathrm{~K}$ but $62 \%$ at $10 \mathrm{~K}$ ) when compared with 2-Dy ( $85 \%$ on the whole temperature range). Similarly, 1-Dysolid has very high $\alpha$ values $(0.59$ at $1.8 \mathrm{~K}$ and 0.41 at $10 \mathrm{~K})$ whereas the highest $\alpha$ observed on 2-Dy was 0.177 at $7.5 \mathrm{~K}$ (Table S3, Figure S8).We therefore observe that, even if 1-Dy and 2-Dy have a first coordination sphere made of the same atoms $\left(\mathrm{N}_{3} \mathrm{O}_{5}\right)$ and the same coordination polyhedron symmetry $\left(\mathrm{D}_{2 \mathrm{~d}}\right)$, their resulting magnetic properties are significantly different. Indeed, the change of the four oxygen atoms that do not belong to the merocyanine ligand (four $\mathrm{O}_{\text {hfac }}$ in 2-Dy for two $\mathrm{O}_{\text {water }}$ plus two $\mathrm{O}_{\text {triflate }}$ in 1-Dy) induces a different charge density on the corresponding oxygen and a different crystal-field splitting associated with a smaller barrier for relaxation. This aspect can be evaluated through CASSCF/SI-SO calculations. In the case of 1-Dy, the calculations lead to a remarkably pure $\left|\mathrm{M}_{\mathrm{j}}\right\rangle= \pm 15 / 2$ ground state wavefunction corresponding to a complex with a high axial anisotropy, the ground state $g$ tensor having almost no contribution in the xy plane $\left(\mathrm{g}_{\mathrm{x}}=0.00, \mathrm{~g}_{\mathrm{y}}=0.00, \mathrm{~g}_{\mathrm{z}}=19.69\right.$, Table S8). The magnetic anisotropy axis is calculated collinear to the Dy- $\mathrm{O}_{\text {phenolate }}$ bond (Figure 1). This is pretty similar to that of 2-Dy with an important axial character but a clear difference comes from the separation to the first excited state which is of $138 \mathrm{~cm}^{-1}$ for 1-Dy, about two third the value obtained for 2-Dy $\left(211 \mathrm{~cm}^{-1}\right)$. Experimentally this drop in the barrier is much more dramatic and we conclude that other mechanisms than the pure thermally activated relaxation are significantly enhanced in 1-Dy. Indeed, the subtle differences in the molecular structure and in 
the lattice between the two complexes are likely to impact temperature-independent relaxation phenomena as illustrated by the very high $\alpha$ values observed on 1-Dysolid that indicate a competition between several magnetic relaxation processes. Thus, the comparison between 1-Dy and 2-Dy is a sound illustration that barely any change in the close environment of the dysprosium center has a massive impact on the dynamic magnetic properties and for that reason, dynamic magnetic measurements can be considered as a very sensitive probe of the coordination sphere of dysprosium(III).

\section{Magnetic investigation in frozen solutions.}

Ac magnetic measurements have been performed on 1-Dysolution and 1-Dyphoto using the same procedure than for 1-Dysolid. The measurements were conducted on a solution prepared in the same conditions (irradiation time and power, concentration, solvent) used for the NMR investigation of cis-1-Y and we can assume that the content of 1-Dyphoto is a mixture of about 78 $\%$ of cis-1-Dy and $22 \%$ of 1-Dy (see experimental part). 1-Dysolution shows a behavior very similar to the one of 1-Dysolid with a similar energy barrier $\left(\Delta=35.4 \mathrm{~K}\left(24.6 \mathrm{~cm}^{-1}\right)\right)$, similar temperature dependence of $\tau\left(\tau_{0}=4.5110^{-6} \mathrm{~s} ; \tau_{\text {tunnel }}=0.14 \mathrm{~s}(1.13 \mathrm{~Hz})\right)$ and similar relaxing fraction (99\% at $1.8 \mathrm{~K}$ and $66 \%$ at $10 \mathrm{~K}$ ) (Tables S4-S45, Figures 4, 5 and S7). This is a proof that the electrostatic environment around the Dy ${ }^{\mathrm{III}}$ ion is unaffected by solubilization (Figure 4). This is a key point as SMM with magnetic relaxation that is preserved upon solubilization are quite rare. ${ }^{[21]}$ Additionally, the distribution of $\tau$ is remarkably optimized in $\mathbf{1 - D y}$ solution with lower $\alpha$ values $(0.37$ at $1.8 \mathrm{~K}$ and 0.24 at $10 \mathrm{~K})$ than $\mathbf{1 - D y}$ solid. This is quite different from what is usually observed because the distribution of molecular distortion in frozen solutions usually induces high $\alpha$ values. It is not the case for $\mathbf{1 - D y}$ which can be considered as a stable and "rigid" 
molecule in solution. Consequently the high $\alpha$ values observed on $\mathbf{1 - D y}$ solid are likely to be due to weak intermolecular interactions.

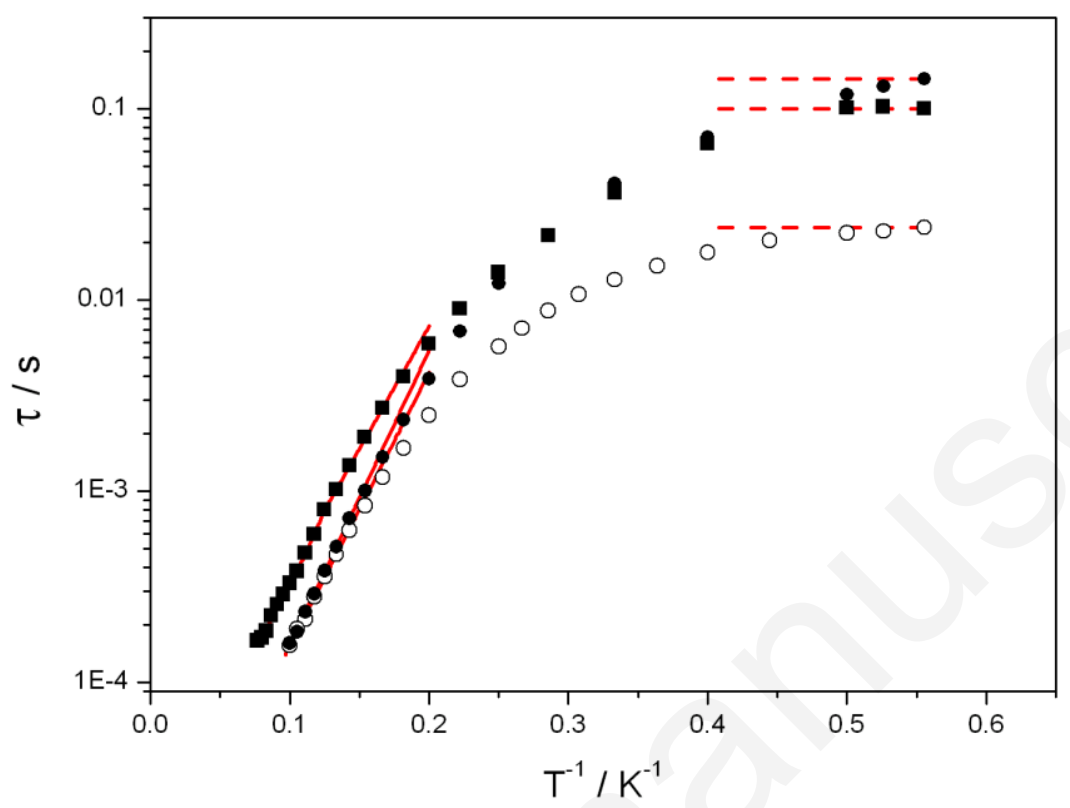

Figure 5: Temperature dependence of the relaxation time $(\tau)$ for 1-Dysolid (squares), 1-Dysolution (circles), 1-Dyphoto (empty circles). Red lines are relaxation processes estimations (see main text).

After blue light irradiation $(\lambda=450 \mathrm{~nm})$, 1-Dyphoto shows similar magnetic relaxation than 1Dysolution and further confirms the robustness of the electrostatic environment around of the Dy ${ }^{\mathrm{III}}$ ion even upon photo-conversion.. Magnetic behavior above $5 \mathrm{~K}$ is close to the one of 1-Dysolution $\left.\left(\Delta=32.9 \mathrm{~K}\left(22.9 \mathrm{~cm}^{-1}\right)\right), \tau_{0}=5.7610^{-6} \mathrm{~s}\right)$ but the temperature independent relaxation accelerates by one order of magnitude below $2 \mathrm{~K}\left(\tau_{\mathrm{tunnel}}=0.023 \mathrm{~s}, 6.6 \mathrm{~Hz}\right)$. Accordingly, the relaxing fraction decreases $(95 \%$ at $1.8 \mathrm{~K}$ and $48 \%$ at $10 \mathrm{~K})$ and $\alpha$ decreases $(0.52$ at $1.8 \mathrm{~K}$ and 0.30 at $10 \mathrm{~K})$ (Tables S6-S7, Figures S8). This sustains the findings that the electrostatic changes induced by the photo-conversion are far from the DyIII neighboring since they only impact its low temperature temperature-independent relaxation. 
To sum up, the magnetic investigation on 1-Dy demonstrates that the substitution of the Dy ${ }^{\mathrm{III}}$ coligand from hfac $^{-}$to $\mathrm{OTf}^{-}$has a deleterious effect on the resulting magnetic SMM properties. On the other hand, the SMM behavior is remarkably unchanged upon solubilization. Interestingly, efficient photo-conversion could be driven and was demonstrated to accelerate the low temperature magnetic relaxation while the high temperature $(\mathrm{T}>5 \mathrm{~K})$ behavior remained the same. All these observations support the photo-conversion to the cis isomer of the dysprosium complex in which only the periphery of the coordination sphere change upon isomerization.

\begin{tabular}{|c|c|c|c|c|c|c|c|}
\hline & $\begin{array}{c}\Delta \\
(\mathrm{K})\end{array}$ & $\begin{array}{l}\tau_{0} \\
(\mathrm{~s})\end{array}$ & $\begin{array}{c}\tau_{\text {tunnel }} \\
(\mathrm{s})\end{array}$ & & & & \\
\hline & & & & $1.8 \mathrm{~K}$ & $10 \mathrm{~K}$ & $1.8 \mathrm{~K}$ & $10 \mathrm{~K}$ \\
\hline 2-Dy & 216 & $4.710^{-9}$ & - & 85 & 85 & 0.17 & 0.07 \\
\hline 1-Dy $y_{\text {solid }}$ & 32.9 & $1.2410^{-5}$ & 0.10 & 96 & 62 & 0.59 & 0.41 \\
\hline $\begin{array}{l}\text { 1- } \\
\text { Dysolution }\end{array}$ & 35.4 & $4.5110^{-6}$ & 0.14 & 99 & 66 & 0.37 & 0.24 \\
\hline 1-Dyphoto & 32.9 & $5.7610^{-6}$ & 0.023 & 95 & 48 & 0.52 & 0.30 \\
\hline
\end{tabular}

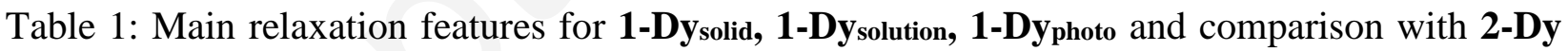
(from ref [12]).

\section{Conclusion.}

The synthesis of two complexes of a chelating merocyanine ligand has been performed through the reaction of a bis(pyridinemethyl)amine substituted spiropyran with yttrium(III) or dysprosium(III) triflate salts. Their structure, established both in the solid state by single crystal X-ray diffraction studies and in solution by ${ }^{1} \mathrm{H}$ NMR, results from coordination induced opening of the spiropyran moiety, as previously shown in the case of $\left[\mathrm{M}(\mathrm{hfac})_{3}\right]$ precursors. ${ }^{[12]}$ However, 
the light switching behavior of the complexes presented herein is unique since they can reversibly undergo a photo-triggered transformation consisting of an unusual isomerization of the MC ligand to the cis-MC complex in which the metal-phenolate bond is maintained. This could be proven by NMR investigations on the diamagnetic yttrium complex and by AC susceptibility studies on the dysprosium complex. Our observations on both series of complexes (1-Dy and 2Dy) stress the importance of the strong merocyanine phenolate to metal O-M bond in driving the magnetic anisotropy of the system, suggesting that the SMM behavior would likely be lost upon photo-conversion to the spiropyran form of the complex, which requires the breaking of this bond. However, in the case of our lanthanide complexes, the O-M bond is also essential for stability and cannot be broken to generate the SP isomer so that light irradiation produces either a decoordinated species (case of 2-Dy) or partial isomerization to a cis form of the merocyanine (case of 1-Dy). Our current efforts are therefore focused on designing complexes with improved stability in the spiropyran form, in order to reach fully operational photomagnetic systems.

Conflict of interest. The authors acknowledge that there are no conflicts of interest to declare.

Acknowledgments. This work was supported by Université de Rennes 1, CNRS, Agence Nationale de la Recherche (RuOxLux - ANR-12-BS07-0010-01)), INSA Rennes, Chinese Scholarship Council. B.L.G. thanks the French GENCI/IDRIS-CINES center for high-performance computing resources.

Supporting Information Available: additional magnetic data and calculations results.

\section{Experimental Section.}


General comments: Solvents as well as yttrium and dysprosium triflate salts (STREM) were used as purchased. The ligand LsP was synthesized as previously described. ${ }^{[12]}$ High resolution mass spectra (HRMS) were recorded in Rennes at the CRMPO (Centre Régional de Mesures Physiques de 1'Ouest) on a Bruker MicrO-Tof-Q II. ${ }^{1} \mathrm{H}$ NMR spectra were recorded on a 500 $\mathrm{MHz}$ Bruker Avance I instrument and ${ }^{19} \mathrm{~F}$ NMR were recorded on a $400 \mathrm{MHz}$ Bruker Avance III instrument.

Blue irradiations were performed in QS UV cells or in NMR tubes with a LS series Light Source of ABET technologies, Inc (150 W Xenon lamp) with $10 \mathrm{~nm}$ bandpass light filters centered at $450 \mathrm{~nm}$. Irradiation at $254 \mathrm{~nm}$ was done with a UV-lamp used for TLC illumination.

1-Y: Y(OTf) 3 (15 mg, $0.028 \mathrm{mmol}, 1$ eq.) and ligand LsP (30 mg, $0.056 \mathrm{mmol}, 2$ eq.) were dissolved in $0.6 \mathrm{~mL}$ of dichloromethane and kept at room temperature. After two days, the reaction mixture afforded red crystals which were collected by filtration on filter paper and airdried. The yield was $42 \%$ (14 mg). A crystal suitable for XRD diffraction was selected from this batch. ${ }^{1} \mathrm{H}$ NMR (400 MHz, $\left.\mathrm{CD}_{3} \mathrm{CN}, \mathrm{ppm}\right): \delta=1.86$ (s, 6H, $\left.\mathrm{CMe}_{2}\right), 3.73$ (br s, 2H, $\mathrm{H}_{\mathrm{d}}$ ), 4.10 (s, 3H, N-Me), 4.16 (d, J = 15.5 Hz, 2H, $\mathrm{H}_{\mathrm{e}}$ or $\mathrm{H}_{\mathrm{e}}$ ), 4.64 (d, J = $15.5 \mathrm{~Hz}, 2 \mathrm{H}, \mathrm{H}_{\mathrm{e}}$ or $\mathrm{H}_{\mathrm{e}}$ ), 7.37 (br s, 4H, Hb, Hb'), 7.77 (d, J = 16.0 Hz, 1H, Ha/b), 7.79-7.66 (m, 4H), 7.86 (br s, 2H), 8.12 (m, 1H,), $8.15\left(\mathrm{~d}, \mathrm{~J}=16.0 \mathrm{~Hz}, 1 \mathrm{H}, \mathrm{H}_{\mathrm{a} / \mathrm{b}}\right), 8.30(\mathrm{~d}, \mathrm{~J}=2.9 \mathrm{~Hz}, 1 \mathrm{H}), 8.79(\mathrm{br} \mathrm{s}, 2 \mathrm{H})$. See Figure 4 for numbering. ${ }^{19} \mathrm{~F}$ NMR (376 MHz, $\left.\mathrm{CDCl}_{3}, \mathrm{ppm}\right):-79.2 \mathrm{ppm}$. FT-IR $\left(\mathrm{cm}^{-1}, \mathrm{ATR}\right)=3344\left(\mathrm{v}_{\mathrm{O}-\mathrm{H}}\right)$, $1321,1294,1220,1211,1157,1026\left(v_{\mathrm{C}-\mathrm{F}}\right)$ and $1462\left(v_{\mathrm{C}=\mathrm{C}}\right)$. Elemental analysis calcd $(\%)$ for $\mathrm{C}_{35} \mathrm{H}_{35} \mathrm{~N}_{5} \mathrm{O}_{14} \mathrm{~F}_{9} \mathrm{~S}_{3} \mathrm{Y}_{\text {. }} \mathrm{CH}_{2} \mathrm{Cl}_{2}$ : C 36.31; H 3.13; N 5.88. S 8.08; found $\mathrm{C} 35.94 ; \mathrm{H}$ 3.15; N 5.71; S 7.81. HRMS (EI) for $\mathrm{C}_{34} \mathrm{H}_{31} \mathrm{~N}_{5} \mathrm{O}_{9} \mathrm{~F}_{6} \mathrm{~S}_{2} \mathrm{Y}^{+}$(920.0520): $920.0523\left(\mathrm{M}^{+}\right)$.

1-Dy: Dy(OTf) 3 (18 mg, 0.029 mmol, 1 eq.) and ligand Lsp (31 mg, $0.058 \mathrm{mmol}, 2$ eq.) were dissolved in $0.6 \mathrm{~mL}$ of dichloromethane and kept at room temperature. After two days, the reaction mixture afforded red crystals which were collected by filtration on filter paper and airdried. The yield was $30 \%(11 \mathrm{mg})$. A crystal suitable for XRD diffraction was selected from this batch. FT-IR $\left(\mathrm{cm}^{-1}\right.$, ATR $)=3354\left(v_{\mathrm{O}-\mathrm{H}}\right), 1321,1296,1247,1222,1157,1026\left(v_{\mathrm{C}-\mathrm{F}}\right)$ and 1469 $\left(v_{\mathrm{C}=\mathrm{C}}\right)$. Elemental analysis calcd $(\%)$ for $\mathrm{C}_{35} \mathrm{H}_{35} \mathrm{~N}_{5} \mathrm{O}_{14} \mathrm{~F}_{9} \mathrm{~S}_{3} \mathrm{Dy} \cdot \mathrm{CH}_{2} \mathrm{Cl}_{2}$ : C 34.20; H 2.95; N 5.54; S 7.61; found C 34.18; H 3.06; N 5.63; S 7.42. HRMS (EI) for $\mathrm{C}_{34} \mathrm{H}_{31} \mathrm{~N}_{5} \mathrm{O}_{9} \mathrm{~F}_{6} \mathrm{~S}_{2} \mathrm{Dy}^{+}$(995.0753): $995.0756\left(\mathrm{M}^{+}\right)$. 
Photo-isomerization study by ${ }^{\mathbf{1}} \mathbf{H}$ NMR. A solution of $6 \mathrm{mg}$ of $\mathbf{1 - Y}$ in $200 \mu \mathrm{L}$ of $d^{3}$-acetonitrile placed in an NMR tube was irradiated for 17 hours at $450 \mathrm{~nm}$, and then diluted to a total volume of $1.0 \mathrm{~mL}$ before NMR measurement. This solution was either stored in the dark for 14 days or irradiated for $10 \mathrm{~h}$ at $254 \mathrm{~nm}$. The ratio between the two isomers was calculated based on the integration ratio of the methyl groups signal at $1.86(\mathbf{1 - Y})$ and 1.70 (cis-1-Y) ppm. It was $100 \%$ 1-Y in the initial state, 22:78 1-Y/cis-1-Y after $450 \mathrm{~nm}$ irradiation, 81:19 1-Y/cis-1-Y after resting in the dark for 14 days and 71:29 after $254 \mathrm{~nm}$ irradiation for $10 \mathrm{~h}$.

Photo-isomerization study by SQUID magnetometry. A solution of $9 \mathrm{mg}$ of 1-Dy in $490 \mu \mathrm{L}$ of $d^{3}$-acetonitrile was splitted into two. First, $200 \mu \mathrm{L}$ were placed in a glass tube and introduced into the magnetometer in order to measure the initial state as frozen solution. The remaining solution was placed in an NMR tube and was irradiated for 15 hours at $450 \mathrm{~nm}$. After this time, $200 \mu \mathrm{L}$ were introduced in the magnetometer in order to measure the photo-induced state, while the remaining solution was submitted to absorption spectroscopy measurement after dilution in order to confirm the reaching of the photostationary state which content is considered the same as in the NMR experiment (22:78 1-Y/cis-1-Y).

Computational details. Wavefunction-based calculations were carried out on the molecular structure of 1-Dy by using the SA-CASSCF/RASSI-SO approach, as implemented in the MOLCAS quantum chemistry package (versions 8.0). ${ }^{[22]}$ In this approach, the relativistic effects are treated in two steps on the basis of the Douglas-Kroll Hamiltonian. First, the scalar terms were included in the basis-set generation and were used to determine the spin-free wavefunctions and energies in the complete active space self-consistent field (CASSCF) method. ${ }^{[23]}$ Next, spinorbit coupling was added within the restricted-active-space-state-interaction (RASSI-SO) method, which uses the spin-free wavefunctions as basis states. ${ }^{[24]}$ The resulting wavefunctions and energies are used to compute the magnetic properties and g-tensors of the lowest states from the energy spectrum by using the pseudo-spin $S=1 / 2$ formalism in the SINGLE-ANISO routine. ${ }^{[25]}$ Cholesky decomposition of the bielectronic integrals was employed to save disk space and speed-up the calculations. ${ }^{[26]}$ The active space of the self-consistent field (CASSCF) method consisted of the nine $4 \mathrm{f}$ electrons of the Dy ${ }^{\mathrm{III}}$ ion spanning the seven $4 \mathrm{f}$ orbitals, i.e. CAS(9,7)SCF. State-averaged CASSCF calculations were performed for all of the sextets (21 roots), all of the quadruplets (224 roots), and 300 out of the 490 doublets (due to software 
limitations) of the Dy ${ }^{\mathrm{III}}$ ion. Twenty-one sextets, 128 quadruplets, and 107 doublets were mixed through spin-orbit coupling in RASSI-SO. All atoms were described by ANO-RCC basis sets. ${ }^{\text {[27] }}$ The following contractions were used: [8s7p4d3f2g1h] for Dy, [4s3p2d] for the $\mathrm{O}$ and $\mathrm{N}$ atoms directly coordinated to $\mathrm{Dy},[3 \mathrm{~s} 2 \mathrm{p}$ ] for the $\mathrm{C}$ and $\mathrm{F}$ atoms and other $\mathrm{O}$ and $\mathrm{N}$ atoms, and [2s] for the $\mathrm{H}$ atoms. The atomic positions were extracted from the X-ray crystal structures. Only the position of the $\mathrm{H}$ and $\mathrm{F}$ atoms were optimized on the $\mathrm{Y}^{\mathrm{III}}$ parent complex with the Gaussian 09 (revision D.01) package, ${ }^{[28]}$ employing the PBE0 hybrid functional. ${ }^{[29]}$ The "Stuttgart/Dresden" basis sets and effective core potentials were used to describe the yttrium atom, ${ }^{[30]}$ whereas all other atoms were described with the SVP basis sets. ${ }^{[31]}$

\section{Bibliography}

[1] a) R. J. G. John C. Crano, in Topics in Applied Chemistry, Vol. 1, Main photochromic families (Ed.: G. J. S. Alan R. Katritzky), Kluwer Academic Publisher, 2002; b) G. Berkovic, V. Krongauz, V. Weiss, Chem. Rev. 2000, 100, 1741-1753; c) M. M. Russew, S. Hecht, Adv. Mater. 2010, 22, 3348-3360; d) S. V. Paramonov, V. Lokshin, O. A. Fedorova, J. Photochem. Photobiol C 2011, 12, 209-236; e) J. J. Zhang, Q. Zou, H. Tian, Adv. Mater. 2013, 25, 378-399; f) M. Natali, S. Giordani, Chem. Soc. Rev. 2012, 41, 4010-4029.

[2] V. I. Minkin, Chem. Rev. 2004, 104, 2751-2776.

[3] Z. Y. Tian, A. D. Q. Li, Acc. Chem. Res. 2013, 46, 269-279.

[4] a) R. Klajn, Chem. Soc. Rev. 2014, 43, 148-184; b) Q. Qi, C. Li, X. Liu, S. Jiang, Z. Xu, R. Lee, M. Zhu, B. Xu, W. Tian, J. Am. Chem. Soc. 2017.

[5] a) J. T. C. Wojtyk, P. M. Kazmaier, E. Buncel, Chem. Mater. 2001, 13, 2547-2551; b) M. Kubinyi, O. Varga, P. Baranyai, M. Kallay, R. Mizsei, G. Tarkanyi, T. Vidoczy, J. Mol. Struct. 2011, 1000, 77-84; c) Y. Hasegawa, T. Nakagawa, T. Kawai, Coord. Chem. Rev. 2010, 254, 2643-2651; d) M. C. Walkey, L. T. Byrne, M. J. Piggott, P. J. Low, G. A. Koutsantonis, Dalton Trans. 2015, 44, 8812-8815; e) M. M. Paquette, B. O. Patrick, N. L. Frank, J. Am. Chem. Soc. 2011, 133, 10081-10093.

[6] M. Baldrighi, G. Locatelli, J. Desper, C. B. Aakeröy, S. Giordani, Chem. Eur. J. 2016, 22, 13976-13984.

[7] a) C. Tu, E. A. Osborne, A. Y. Louie, Tetrahedron 2009, 65, 1241-1246; b) C. Tu, A. Y. Louie, Chem. Commun. 2007, 1331-1333.

[8] a) R. Sessoli, A. K. Powell, Coord. Chem. Rev. 2009, 253, 2328-2341; b) D. Gatteschi, R. Sessoli, J. Villain, Molecular Nanomagnets, Oxford University Press, Oxford, 2006; c) C. Benelli, D. Gatteschi, Introduction to Molecular Magnetism, From transition metals to lanthanides, Wiley-VCH, Weinheim, Germany, 2015; d) S. Demir, I.-R. Jeon, J. R. Long, T. D. Harris, Coord. Chem. Rev. 2015, 289, 149-176; e) D. N. Woodruff, R. E. P. Winpenny, R. A. Layfield, Chem. Rev. 2013, 113, 5110-5148; f) J. Ferrando-Soria, J. Vallejo, M. Castellano, J. Martínez-Lillo, E. Pardo, J. Cano, I. Castro, F. Lloret, R. RuizGarcía, M. Julve, Coord. Chem. Rev. 2017, 339, 17-103; g) Molecular nanomagnets and 
related phenomena, Vol. 164, Springer, 2015; h) K. Liu, W. Shi, P. Cheng, Coord. Chem. Rev. 2015, 289-290, 74-122.

[9] a) N. Ishikawa, M. Sugita, T. Ishikawa, S. Koshihara, Y. Kaizu, J. Am. Chem. Soc. 2003, 125, 8694-8695; b) J. D. Rinehart, J. R. Long, Chem. Sci. 2011, 2, 2078-2085; c) S. T. Liddle, J. van Slageren, Chem. Soc. Rev. 2015, 44, 6655-6669; d) F. Pointillart, O. Cador, B. Le Guennic, L. Ouahab, Coord. Chem. Rev. 2017, 346, 150-175; e) S. G. McAdams, A.-M. Ariciu, A. K. Kostopoulos, J. P. S. Walsh, F. Tuna, Coord. Chem. Rev. 2017, 346, 216-239; f) Y.-S. Meng, S.-D. Jiang, B.-W. Wang, S. Gao, Acc. Chem. Res. 2016, 49, 2381-2389; g) S. Gómez-Coca, D. Aravena, R. Morales, E. Ruiz, Coord. Chem. Rev. 2015, 289-290, 379-392.

[10] a) C. A. P. Goodwin, F. Ortu, D. Reta, N. F. Chilton, D. P. Mills, Nature 2017, 548, 439442; b) F. C. a. Y. L. a. W. W. a. Jiang Liu and Yan-Cong Chen and Jun-Liang Liu and Veacheslav Vieru and Liviu Ungur and Jian-Hua Jia and Liviu, J. Am. Chem. Soc. 2016, 138, 5441-5450; c) L. Norel, L. E. Darago, B. Le Guennic, K. Chakarawet, M. I. Gonzalez, J. H. Olshansky, S. Rigaut, J. R. Long, Angew. Chem. Int. Ed., n/a-n/a; d) Y.-S. Ding, N. F. Chilton, R. E. P. Winpenny, Y.-Z. Zheng, Angew. Chem. Int. Ed. 2016, 55, 16071-16074; e) S. K. Gupta, T. Rajeshkumar, G. Rajaraman, R. Murugavel, Chem. Sci. 2016, 7, 5181-5191; f) F.-S. Guo, B. M. Day, Y.-C. Chen, M.-L. Tong, A. Mansikkamäki, R. A. Layfield, Angew. Chem. Int. Ed. 2017, 56, 11445-11449.

[11] a) D. Pinkowicz, M. Ren, L. M. Zheng, S. Sato, M. Hasegawa, M. Morimoto, M. Irie, B. K. Breedlove, G. Cosquer, K. Katoh, M. Yamashita, Chem. Eur. J. 2014, 20, $12502-$ 12513; b) G. Cosquer, B. K. Breedlove, M. Yamashita, Dalton Trans. 2015, 44, 29362942; c) L.-F. Wang, J.-Z. Qiu, J.-L. Liu, Y.-C. Chen, J.-H. Jia, J. Jover, E. Ruiz, M.-L. Tong, Chem. Commun. 2015, 15358-15361.

[12] P. Selvanathan, G. Huang, T. Guizouarn, T. Roisnel, G. Fernandez-Garcia, F. Totti, B. Le Guennic, G. Calvez, K. Bernot, L. Norel, S. Rigaut, Chem. Eur. J. 2016, 22, 1522215226.

[13] P. Nuernberger, S. Ruetzel, T. Brixner, Angew. Chem. Int. Ed. 2015, 54, 11368-11386.

[14] P. B. Markworth, B. D. Adamson, N. J. A. Coughlan, L. Goerigk, E. J. Bieske, PCCP 2015, 17, 25676-25688.

[15] Y. Kalisky, D. J. Williams, Macromolecules 1984, 17, 292-296.

[16] a) Z. Miskolczy, L. Biczok, J. Phys. Chem. B 2011, 115, 12577-12583; b) Z. Miskolczy, L. Biczók, J. Phys. Chem. B 2013, 117, 648-653.

[17] D. Casanova, M. Llunell, P. Alemany, S. Alvarez, Chem. Eur. J. 2005, 11, 1479-1494.

[18] Z. Miskolczy, L. Biczók, TJ. Phys. Chem. B 2011, 115, 12577-12583.

[19] a) E. Bakeir, G. M. Attia, M. Lukyanova, B. Lukyanov, M. S. A. Abdel-Mottaleb, Research Letters in Physical Chemistry 2008, 2008, 4; b) M. S. Attia, M. H. Khalil, M. S. A. Abdel-Mottaleb, M. B. Lukyanova, Y. A. Alekseenko, B. Lukyanov, International Journal of Photoenergy 2006, 2006, 9.

[20] a) J. Long, B. G. Shestakov, D. Liu, L. F. Chibotaru, Y. Guari, A. V. Cherkasov, G. K. Fukin, A. A. Trifonov, J. Larionova, Chem. Commun. 2017; b) P.-E. Car, M. Perfetti, M. Mannini, A. Favre, A. Caneschi, R. Sessoli, Chem. Commun. 2011, 47, 3751-3753.

[21] T. T. da Cunha, J. Jung, M. E. Boulon, G. Campo, F. Pointillart, C. L. M. Pereira, B. Le Guennic, O. Cador, K. Bernot, F. Pineider, S. Golhen, L. Ouahab, J. Am. Chem. Soc. 2013, 135, 16332-16335. 
[22] F. Aquilante, L. De Vico, N. Ferré, G. Ghigo, P.-å. Malmqvist, P. Neogrády, T. B. Pedersen, M. Pitoňák, M. Reiher, B. O. Roos, L. Serrano-Andrés, M. Urban, V. Veryazov, R. Lindh, J. Comput. Chem. 2010, 31, 224-247.

[23] B. O. Roos, P. R. Taylor, P. E. M. Siegbahn, Chem. Phys. 1980, 48.

[24] a) P.-å. Malmqvist, B. O. Roos, Chem. Phys. Lett. 1989, 155, 189-194; b) P.-å. Malmqvist, B. O. Roos, B. Schimmelpfennig, Chem. Phys. Lett. 2002, 357, 230-240.

[25] a) L. F. Chibotaru, L. Ungur, The Journal of Chemical Physics 2012, 137, 064112; b) L. F. Chibotaru, L. Ungur, A. Soncini, Angew. Chem. Int. Ed. 2008, 47, 4126-4129.

[26] F. Aquilante, P.-Å. Malmqvist, T. B. Pedersen, A. Ghosh, B. O. Roos, J. Chem. Theory Comput. 2008, 4, 694-702.

[27] a) B. O. Roos, R. Lindh, P.-Å. Malmqvist, V. Veryazov, P.-O. Widmark, J. Phys. Chem. A 2004, 108, 2851-2858; b) B. O. Roos, R. Lindh, P.-Å. Malmqvist, V. Veryazov, P.-O. Widmark, J. Phys. Chem. A 2005, 109, 6575-6579; c) B. O. Roos, R. Lindh, P.-Å. Malmqvist, V. Veryazov, P.-O. Widmark, A. C. Borin, J. Phys. Chem. A 2008, 112, 11431-11435.

[28] M. J. Frisch, G. W. Trucks, H. B. Schlegel, G. E. Scuseria, M. A. Robb, J. R. Cheeseman, G. Scalmani, V. Barone, B. Mennucci, G. A. Petersson, H. Nakatsuji, M. Caricato, X. Li, H. P. Hratchian, A. F. Izmaylov, J. Bloino, G. Zheng, J. L. Sonnenberg, M. Hada, M. Ehara, K. Toyota, R. Fukuda, J. Hasegawa, M. Ishida, T. Nakajima, Y. Honda, O. Kitao, H. Nakai, T. Vreven, J. A. Montgomery, J. E. Peralta, F. Ogliaro, M. Bearpark, J. J. Heyd, E. Brothers, K. N. Kudin, V. N. Staroverov, R. Kobayashi, J. Normand, K. Raghavachari, A. Rendell, J. C. Burant, S. S. Iyengar, J. Tomasi, M. Cossi, N. Rega, J. M. Millam, M. Klene, J. E. Knox, J. B. Cross, V. Bakken, C. Adamo, J. Jaramillo, R. Gomperts, R. E. Stratmann, O. Yazyev, A. J. Austin, R. Cammi, C. Pomelli, J. W. Ochterski, R. L. Martin, K. Morokuma, V. G. Zakrzewski, G. A. Voth, P. Salvador, J. J. Dannenberg, S. Dapprich, A. D. Daniels, Farkas, J. B. Foresman, J. V. Ortiz, J. Cioslowski, D. J. Fox, Gaussian 09 revision A02, Wallingford CT, 2009.

[29] a) J. P. Perdew, K. Burke, M. Ernzerhof, Phys. Rev. Lett. 1996, 77, 3865-3868; b) C. Adamo, V. Barone, J. Chem. Phys. 1999, 110, 6158-6170.

[30] M. Dolg, H. Stoll, H. Preuss, Theoretica Chimica Acta 1993, 85, 441-450.

[31] F. Weigend, R. Ahlrichs, PCCP 2005, 7, 3297-3305. 